\title{
A Hinged-Pad Test Structure for SAND- $-98-1759 C$ Sliding Friction Measurement in Micromachining
}

\author{
Maarten P. de Boer ${ }^{1}$, Jim M. Redmond ${ }^{2}$ and Terry A. Michalske ${ }^{3}$ \\ Sandia National Laboratories, Albuquerque, NM 87185-1080 \\ 1 Intelligent Micromachine Technology, Dept. 1725 \\ 2 Structural Dynamics, Dept. 9234 \\ ${ }^{3}$ Surface and Interface Science, Dept. 1114 \\ www.mdl.sandia.gov/Micromachine
}

CONF-980918- -

\begin{abstract}
We describe the design, modeling, fabrication and initial testing of a new test structure for friction measurement in MEMS. The device consists of a cantilevered forked beam and a friction pad attached via a hinge. Compared to previous test structures, the proposed structure can measure friction over much larger pressure ranges, yet occupies one hundred times less area. The placement of the hinge is crucial to obtaining a well-known and constant pressure distribution in the device. Static deflections on the device were measured and modeled numerically. Preliminary results indicate that friction pad slip is sensitive to friction pad normal force.
\end{abstract}

\section{Introduction}

In Microelectromechanical Systems (MEMS), surface forces can play a relatively large role compared to gravity and inertia, which are the dominating forces at the macroscale. Because surface forces are not well characterized and often difficult to reproduce in MEMS structures, most commercial applications avoid contact between structural members. Examples include accelerometers and gyroscopes [1-3]. An important commercial device in which adhesive contact between moving structures and the substrate is allowed is the Digital Mirror Device [4]. For this product, adhesion (e.g., stiction) and adhesion hysteresis (changes in adhesion over time or due to environment) are important factors in determining device reliability. While great reliability improvement has necessarily been achieved through testing of full scale devices [5], these surface properties can also be studied through the use of test structures [6-8]. From such studies, we hope to understand surface forces in micromachine structures, which may permit us to take advantage of surface characteristics in micromachine design.

If sliding contact between structural members is allowed, a large new class of devices can be brought to product realization in MEMS. Examples include gears for mirror rotation [9], popup mirrors and linear racks [10], and shuffle motors [11]. However, relatively little is understood regarding the friction laws of such devices in contact, such as how friction may scale with apparent pressure $^{\mathrm{T}}$ or sliding velocity. These parameters can vary by orders of magnitude: 0.1 to $100 \mathrm{MPa}$ in apparent pressure and 0.1 to $1000 \mu \mathrm{m} / \mathrm{sec}$, depending on the application. In larger scale devices, friction can depend strongly on these factors [12]. Information on friction of horizontal surfaces in MEMS has been obtained using reciprocating comb drive structures $[13,14]$. According to these data, the coefficient of friction (cof) ranges from about 2-5 for oxide coated polycrystalline silicon (polysilicon) devices to 0.1 for polysilicon devices coated with hydrophobic films. Applied pressures were in the tens of kilopascals. Because the force generated by comb drives is on the order of micronewtons, only a small normal pressure range can be studied for a given test structure. Further, the comb drive consumes a large area to obtain the friction data. In this paper, we consider cantilever beams as potential friction devices. Forces generated can vary from the micronewton to the millinewton level. Hence, a much larger pressure range can potentially be explored at the expense of slip range. Also, with their small footprint, such devices have the potential to serve as parametric test structures. That is, they can provide valuable

\footnotetext{
${ }^{\dagger}$ We distinguish between apparent and true pressure. Apparent pressure is that which can be calculated from contact mechanics assuming smooth surfaces. Actual pressure is that which occurs locally when surface roughness is taken into account. In MEMS, surface texturing of $2-10 \mathrm{~nm} \mathrm{rms} \mathrm{depending} \mathrm{on} \mathrm{processing} \mathrm{of} \mathrm{the} \mathrm{structural} \mathrm{material,} \mathrm{give} \mathrm{rises} \mathrm{to} \mathrm{local}$ pressures at asperity tips 10 to 100 times greater than apparent pressure. Discussion in this paper is limited to apparent pressure.
} 


\section{DISCLAIMER}

This report was prepared as an account of work sponsored by an agency of the United States Government. Neither the United States Government nor any agency thereof, nor any of their employees, makes any warranty, express or implied, or assumes any legal liability or responsibility for the accuracy, completeness, or usefulness of any information, apparatus, product, or process disclosed, or represents that its use would not infringe privately owned rights. Reference herein to any specific commercial product, process, or service by trade name, trademark, manufacturer, or otherwise does not necessarily constitute or imply its endorsement, recommendation, or favoring by the United States Government or any agency thereof. The views and opinions of authors expressed herein do not necessarily state or reflect those of the United States Government or any agency thereof. 


\section{DISCLAIMER}

Portions of this document may be illegible electronic image products. Images are produced from the best available original document. 
information without occupying significant real estate on chips, acting as in-situ diagnostic process monitors.

\section{Conceptual evolution of the test structure}

For an inextensible beam, out-of-plane force applied to a cantilever beam induces slip $\Delta$, according to the relationship

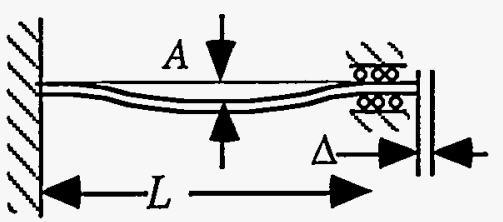

Fig. 1 Slip induced by out-of-plane deflection of amplitude $A$.

$$
\Delta=c \frac{A^{2}}{L}
$$

Here, $A$ is the amplitude of the deflection, $L$ is the length of the beam, and the constant $c \approx 2$ to first order. The slip $\Delta$ is small for such a design; we shall see that it is on the order of $15 \mathrm{~nm}$. An average contact radius between asperities of $10 \mathrm{~nm}$ has been calculated for the rms roughness typical of our polysilicon [15]. Therefore, while the slip is small, it should be sufficient to disengage contacting asperities, and engage asperities at new contacts. Hence, it seems reasonable to expect that a properly designed cantilever structure can incur losses typical of frictional processes in micromachines.

Our goal is to design a friction device which meets the criteria of having independent velocity and pressure control. Although the slip for a cantilever beam is small, the force generated is very large. Therefore, it should be possible to apply a large range of pressures if the device is properly designed.

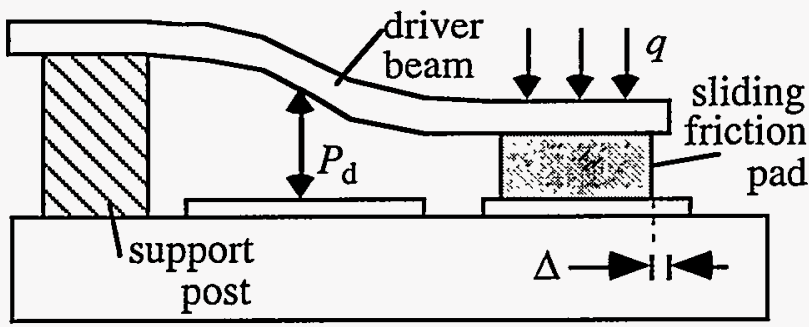

Fig. 2a First concept for friction test structure. This structure fails because the slider block cannot be uniformly maintained in contact with the substrate as driver force $P_{d}$ cycles.

Our first attempt at building a test structure is conceptually represented in Fig. 2a. The driver beam is initially flat and suspended above the substrate, being cantilevered from the left end. The friction pad is brought into contact by the distributed load $q$. Oscillating force $P_{d}$ will cause the slider to move back and forth, with contact area controlled by the design length of the friction pad. Both $q$ and $P_{d}$ are generated by electrostatic forces.

Because of the restoring force of the cantilever, the force $q$ applied to the slider pad cannot immediately cause uniform contact. Beam theory was utilized to understand the deflections in the slider pad area as a function of $P_{d^{*}}$. For this design, we found that the slider pad could not be maintained in contact along its length as $P_{d}$ varied, even for large values of $q$. At $P_{d}=0$, this was physically traced to the connection between the end of the cantilever and the friction pad. To keep the pad in contact along its entire length, the slope must be 0 at this connection.

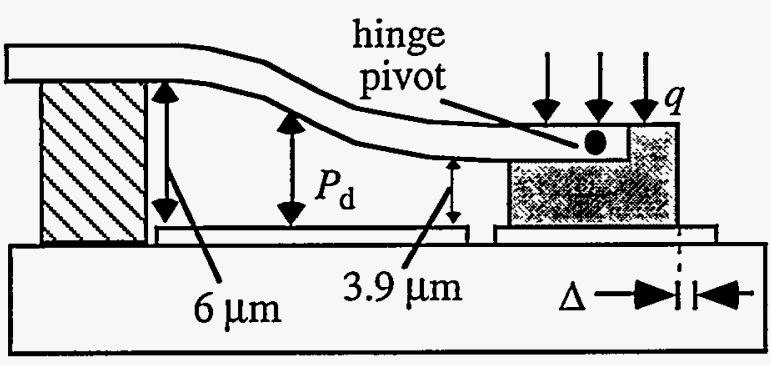

Fig. 2b Improved friction test structure. By connecting to the friction pad via a hinge, a virtually uniform pressure is achieved for relatively small values of $q$.
Enforcement of this condition requires that a moment exist at the connection. However, as the pad becomes flat, the moment vanishes. For example, when applying $40 \mathrm{~V}$ to generate a $q$ of $7,000 \mathrm{~N} / \mathrm{m}^{2}$, the length along the friction $\mathrm{pad}$ which is not touching is approximately 30 microns for $P_{d}=0$. As $P_{d}$ increases, the pad eventually does come perfectly into contact. But for subsequent increase of $P_{d}$, the friction pad rocks about its left bottom corner, leaving only a point contact.

We improved the design as seen in Fig. 2b. Relative to Fig. $2 \mathrm{a}$, the structure differs only 
in its connection between the sliding friction pad and the driver beam, in that now the connection is made by a hinge. The hinge placement allows the contact area of the pad to be virtually

independent of $P_{d}$. This is for two reasons: First, at $P_{d}=0$, the force applied by $q$ on both sides of the hinge allows slope at the connection point to approach 0 at relatively low values of $q$.

Second, as $P_{d}$ increases for a given value of $q$, rocking is resisted because the hinge placement allows the friction pad to extend to the left of the connection between the driver beam and the pad.

The layout and design of the structure is shown in Fig. 3. Fig. 3a is a top view, where it is seen that the hinge is formed by forking the driver beam around the friction pad. In the present work, the length of the driver beam $L_{d}$ is

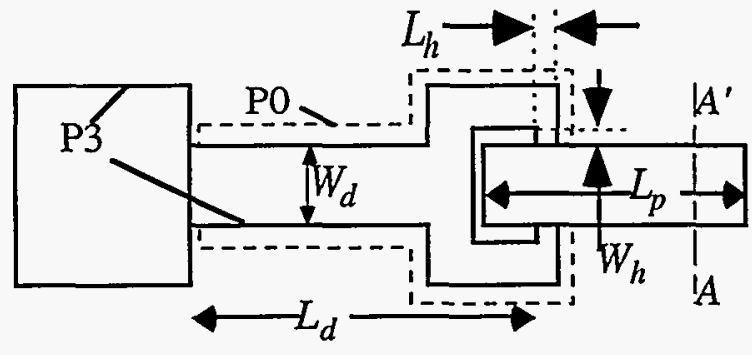

Fig. 3a Top view of the hinged friction pad P3 - poly $3, \mathrm{PO}$ - poly 0 . $500 \mu \mathrm{m}$, the length of the friction pad $L_{p}$ is $200-600 \mu \mathrm{m}$, and the length of the hinge $L_{h}$ is $10 \mu \mathrm{m}$. This hinge length is sufficient to be "stiff", that is, it twists only a small amount due to its high polar moment of inertia. $L_{h}$ can be shortened to $2 \mu \mathrm{m}$ such that the hinge becomes flexible. This further reduces the change in contact area vs. $P_{d}$. However, according to our calculations, axial compliance of a flexible hinge can be a nm or more for large cof. Because the slip $\Delta$ is only about $15 \mathrm{~nm}$, this can reduce the actual slip of the friction pad. The width of the driver beam $W_{d}$ is 50 $\mu \mathrm{m}$ to maximize the axial force developed by the driver beam. The width of the hinge $W_{h}$ is $5 \mu \mathrm{m}$ to minimize its torsional and lateral compliance.

Fig. $3 \mathrm{~b}$ shows a cross-sectional schematic view after poly 3 etch of the friction pad area through section $A A^{\prime}$ of Fig. 3a. Four levels of polysilicon (poly), designated as P0, P1, P2, and $\mathrm{P} 3$ are used to form this part of the structure. Sacrificial oxide layers are designated as SO1, SO2 and SO3. Voltage applied across the poly 1 pad to wings in poly 3 provides normal distributed force $q$ to bring the friction pad into contact with poly 0 at a few volts. Once this occurs, the friction pad acts as a stop, and subsequent voltage applied to poly 1 supplies controllable normal pressure. In this structure, poly 1 is not a necessity; poly 0 could be used instead. However, because of the inverse square relationship of electrostatic force with gap distance, the use of poly 1 allows much higher normal forces to be applied at a given voltage. By taking advantage of conformality in polysilicon deposition, fabrication of the friction pad with a $6 \mu \mathrm{m}$ thick beam is possible. This

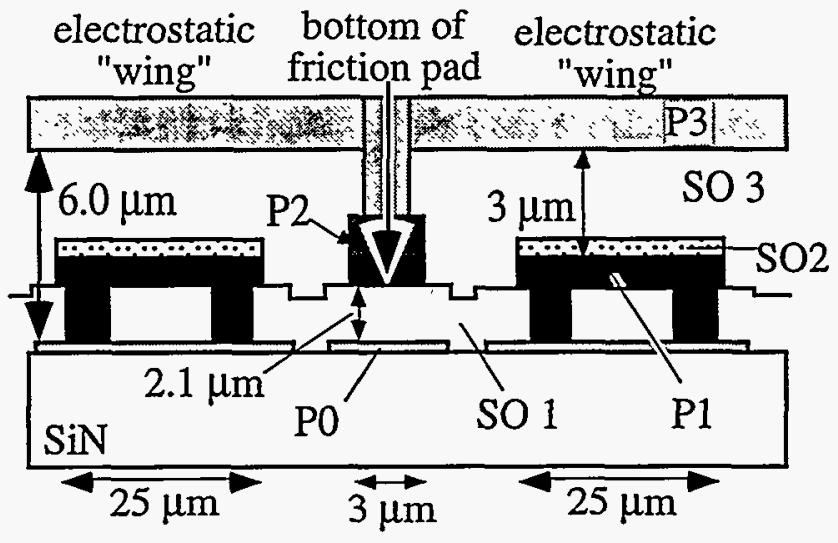

Fig. $3 \mathrm{~b}$ Cross-section through $A A^{\prime}$ of Fig. 3a. $\mathrm{P}$ - poly, $\mathrm{SO}$ - sacrifical oxide. creates a highly uniform pressure across the width of the sliding friction pad because its flexure is extremely small when loaded by the electrostatic wings.

\section{Analytical Modeling}

To derive quantitative trends regarding controllability of the contact area, distributed loading $q$ was assumed in the friction pad region, and point loading $P_{d}$ was applied to the driver pad, as shown in Fig. 4a. The point loading allows simple analytical modeling to be utilized, and deformation trends can be predicted. In the actual experimental situation of Fig. 3a, distributed loading is applied across the driver beam - this will be numerically modeled in the testing section below.

Initially the friction pad is suspended above the surface. As $q$ is increased, it comes into contact with the substrate. Referring to Fig. 4 a, reaction across the length of the friction pad is 
composed of uniform pressure for $x<L_{d^{-}} a_{1}$ and $x>L_{d}+a_{2}$, while point reactions $P_{1}$ and $P_{2}$ act at $x=L_{d}-a_{1}$ and $x=L_{d}+a_{2}$ respectively. To calculate the deflections of the driver beam, these loads can

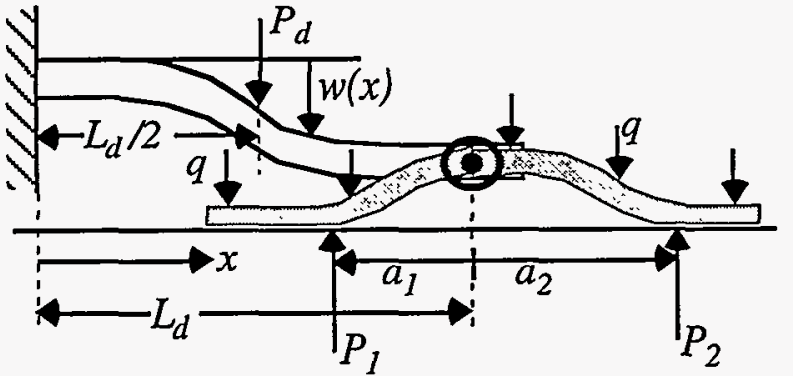

Fig. 4a Beam model used to quantify deflections.

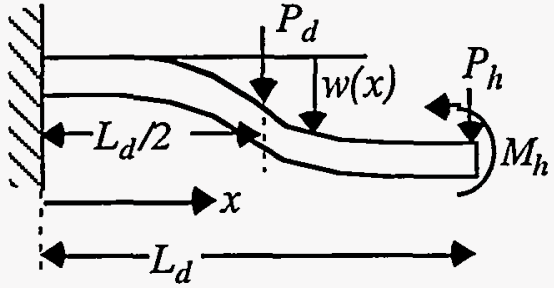

Fig. 4b Transformation to model driver beam.

be reduced to an effective load and moment $P_{h}$ and $M_{h}$ acting at the hinge, as shown in Fig. 4b. Voltages corresponding to the loads required for a given $q$ are represented by $V_{p}$. Electrostatic instabilities [16] in the friction pad region are neglected here. They are not catastrophic because the friction pad acts as a stop. The large effective bending stiffness of the friction pad due to the very thick poly $2 / 3$ stack in the slider region (Fig. 3b) was incorporated in the simulations. To solve for the deflections, the four governing equations for the left and right side of the driver beam and friction pad respectively were expressed. Then, at a given loading, boundary conditions were applied. This gave four equations with four unknowns, which were solved iteratively.

\section{Effect of friction pad loading, $q$}

Two simulations were carried out. In the first, the friction pad was loaded with increasing values of $q$, as represented in Fig. 5. Fig. 5a shows the deflections of the driver pad as well as the friction pad. Fig. $5 \mathrm{~b}$ shows a close-up in the vicinity of the friction pad. At $q=20 \mathrm{~N} / \mathrm{m}^{2}$ (2V), the friction pad just touches the substrate at its right extreme. As $q$ is increased to $350 \mathrm{~N} / \mathrm{m}^{2}$ (8V), the slope of the right hand side of the friction pad becomes 0 , but the left hand side is not yet in contact. The large increase in $q$ from 20 to $350 \mathrm{~N} / \mathrm{m}^{2}$ is because large bending resistance in the friction pad must be overcome. Increasing $q$ to $600 \mathrm{~N} / \mathrm{m}^{2}(10 \mathrm{~V})$, the left hand side of the friction pad comes into contact with the substrate. At $q=1300 \mathrm{~N} / \mathrm{m}^{2}(15 \mathrm{~V})$, the slope of the friction pad becomes 0 at its left end. Observe also that the contact in the right hand of the friction pad has increased considerably - $a_{2}$ has decreased to $29 \mu \mathrm{m}$. Further increases in $q$ reduce both $a_{1}$ and $a_{2}$. At $q=5100 \mathrm{~N} / \mathrm{m}^{2}(30 \mathrm{~V}), a_{1}$ has decreased to $49 \mu \mathrm{m}$ and $a_{2}$ to about $14 \mu \mathrm{m}$.

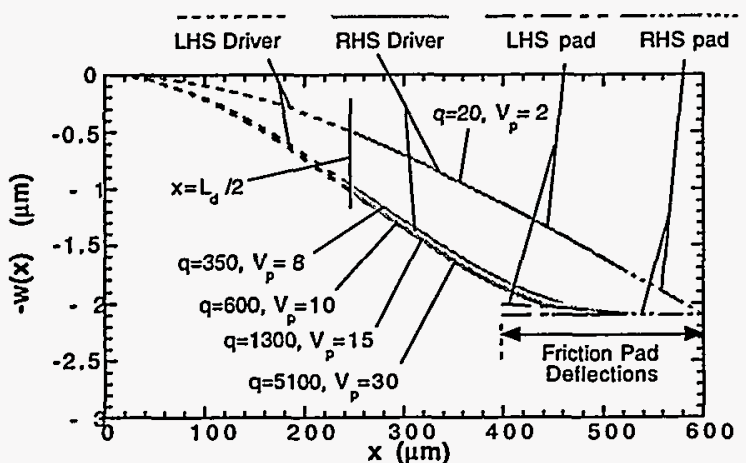

Fig. 5a Deflections for increasing $\mathrm{q}$ with $\mathrm{P}_{\mathrm{d}}=0$

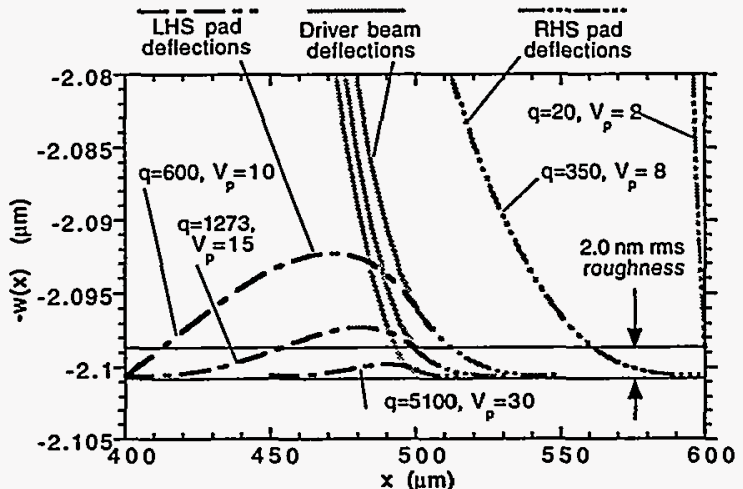

Fig. 5b Close-up near friction pad

Not only do $a_{1}$ and $a_{2}$ decrease substantially, but the deflection of the friction pad over the substrate becomes extremely small. For reference, a typical $2 \mathrm{~nm}$ rms roughness (from atomic force microscopy measurements [17]) of the poly 0 layer is superimposed in Fig. 4b. Considering that for $q=5100 \mathrm{~N} / \mathrm{m}^{2}$, the maximum deflection of $\sim 1 \mathrm{~nm}$ is smaller than the rms roughness of the lower poly layer, the pressure of $5100 \mathrm{~N} / \mathrm{m}^{2}$ decreases only slightly over the curved portion of the 
friction pad. In the smooth beam theory, point load reactions $P_{1}$ and $P_{2}$ act at $x=L_{d}-a_{1}$ and $x=L_{d}+a_{2}$. However, because the friction pad does not lift off the rough surface, these loads will tend to distribute themselves over the sliding interface as well. The effect is opposite to the pressure lowering due to the uplifting of the friction pad. This net cancellation implies that the pressure modulation in the region $L_{d}-a_{1}<x<L_{d}+a_{2}$ is small. Therefore, we have nearly constant pressure along the length of the friction pad for sufficiently high $q$. Contact mechanics of rough surfaces [18] can be invoked to understand the pressure modulation in more detail.

\section{Effect of driver pad loading, $P_{d}$}

In the second simulation, the effect of the driver beam force $P_{d}$ on driver and friction pad deflections at $q=5100 \mathrm{~N} / \mathrm{m}^{2}$ was studied, and the results are graphed in Fig. 6 . In Fig. 6a, the maximum deflection occurs at $P_{d}=284 \mathrm{mN} / \mathrm{m}$. This is because for $P_{d}=0$, the center point of the driver is $(6-1.04)=4.96 \mu \mathrm{m}$ above the substrate. It can deflect one third of this distance before destructive electrostatic instability, i.e., $1.66 \mu \mathrm{m}$. Therefore, the maximum deflection is $(1.04+1.66)=2.70 \mu \mathrm{m}$ at $x=L_{d} / 2$. This limits the total slip of the device.

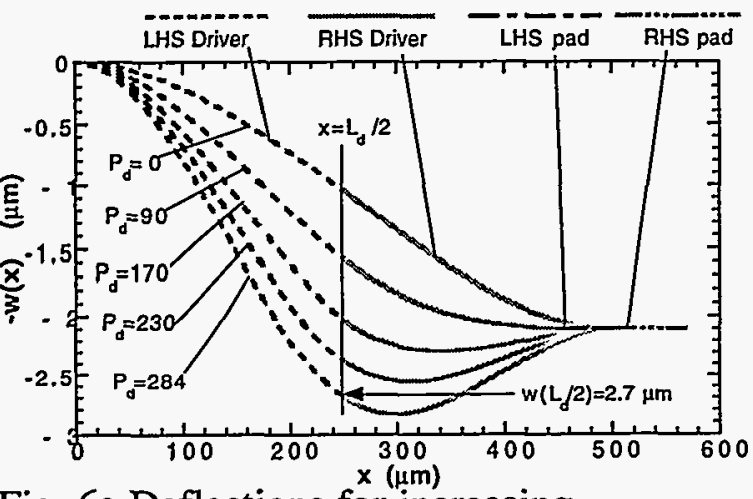

Fig. 6a Deflections for increasing $P_{d}(\mathrm{mN} / \mathrm{m})$ with $\mathrm{q}=5100 \mathrm{~N} / \mathrm{m}^{2}$

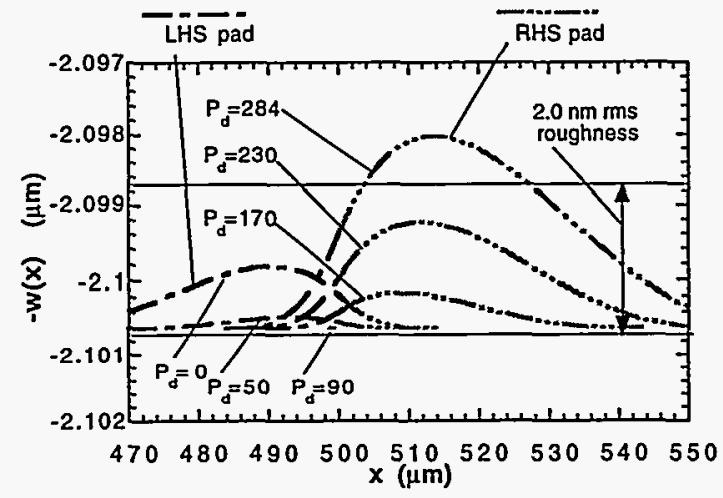

Fig. $6 \mathrm{~b}$ Close-up in friction pad area

In Fig. 6b, a close-up of Fig. $6 \mathrm{a}$ in the friction pad area, $a_{1}$ is greater than $a_{2}$ for $P_{d}<90$ $\mathrm{mN} / \mathrm{m}$ because the driver beam rotation at $x=L_{d}$ is positive. At $P_{d}=90 \mathrm{mN} / \mathrm{m}$, both $a_{1}$ and $a_{2}$ are zero (independent of $q$ ). Effectively only a small point load operates at $x=L_{d}$; the moment vanishes. For $P_{d}>90 \mathrm{mN} / \mathrm{m}, a_{1}$ is less than $a_{2}$ as the driver beam rotation at $x=L_{d}$ rotates counterclockwise to become negative. Note that the pad deflections continue to be less than the rms roughness, except at the largest value of $P_{d}=284 \mathrm{mN} / \mathrm{m}$. Therefore, the modulation of pressure as $P_{d}$ cycles continues to be small, according to the above discussion. In order to minimize the effect of the modulation, most devices were built with pad length $L_{p}=600 \mu \mathrm{m}$ rather than $200 \mu \mathrm{m}$. This assures that the pad has uniform distribution over at least $520 \mu \mathrm{m}$, i.e. $\geq 87 \%$ of the area is contacting at pressure $q=5100 \mathrm{~N} / \mathrm{m}^{2}$ during any part of the cycle.

\section{Relative slip and total friction load}

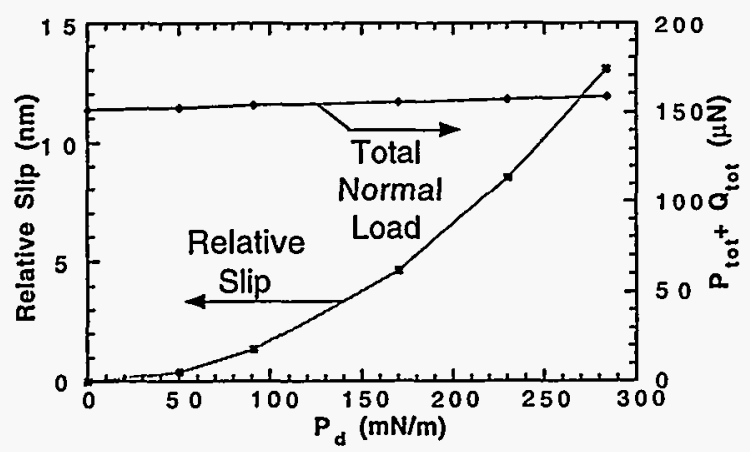

Fig. 7 Relative Slip and Total Normal Load vs. $P_{d}$
Assuming inextensibility of the driver beam, the relative slip of the friction pad vs. $P_{d}$ can be calculated from the arc length formula, and is plotted in Fig. 7 for $q=5100 \mathrm{~N} / \mathrm{m}^{2}$. The slip increases with the square of $P_{d}$, as expected from Eq. (1). The total frictional load consists of the distributed load $q$ times the area of the electrostatic wings, and the point reactions $P_{1}$ and $P_{2}$, times the width of the electrostatic wings. Their sum must increase as $P_{d}$ increases. However, variation of the total normal load is less than $5 \%$ because the normal loading is dominated by $q$, which is independently applied. At $P_{d}=284$, the maximum 
slip is approximately $13 \mathrm{~nm}$. This is the maximum slip possible, and is nearly attainable for reasonably low axial force.

The load which the driver beam must develop in order to cause slip of the friction pad is the product of the coefficient of friction and the normal load. While the slip is small, the driver beam can develop very high axial loads, on the order of several millinewtons. Therefore, it can induce slip of the friction pad over a wide range of coefficient of friction as well as normal load. With $q=5100 \mathrm{~N} / \mathrm{m}^{2}$, the pressure on the slider pad is $5100^{*}(50 / 3)=0.085 \mathrm{MPa}\left(W_{p}=50 \mu \mathrm{m}\right.$, and the width at the bottom of the friction pad is $3 \mu \mathrm{m}$ ). In principle this can be increased; with a pad voltage of $200 \mathrm{~V}$, the applied pressure would be $4 \mathrm{MPa}$. Another order of magnitude increase in pressure may be possible by reducing the Sac Ox 3 thickness, or by designing the friction pad such that it comes into contact with poly 0 only occasionally along its length.

To summarize, modeling results indicate that with the hinged pad structure, above a reasonably small value of $q$, the normal load is controllable, nearly evenly distributed and nearly constant along the length of the friction pad as the driver beam oscillates through its cycle. The slip is small, but perhaps sufficient to allow measurement of the cof. In principle, this device can be tested both statically and dynamically, yielding cof data over a wide experimental pressure and velocity space [19].

Fabrication and testing

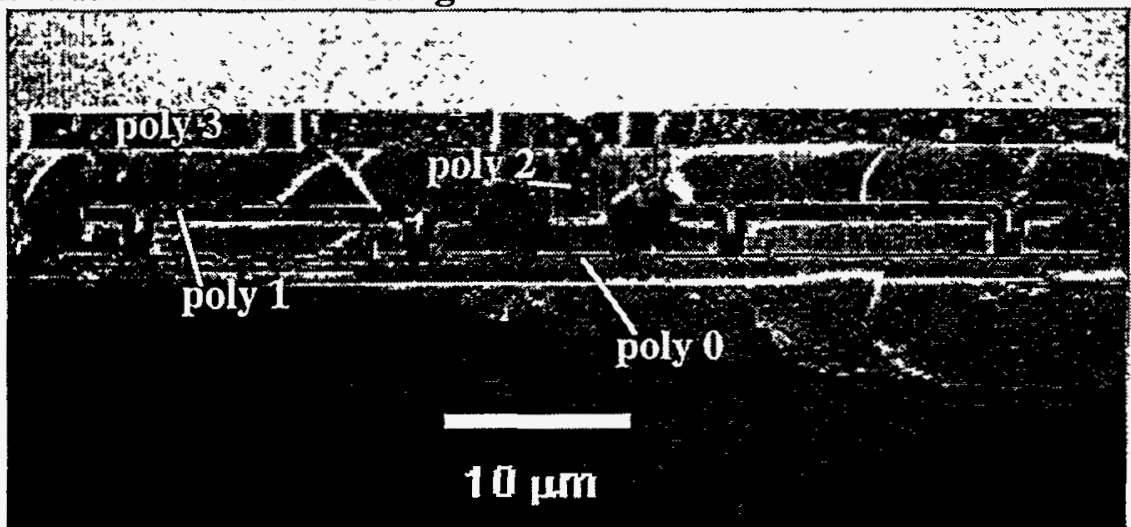

Fig. 8 SEM cross-section of the friction pad. (Compare to Fig. 3b)
The devices were fabricated according to the Sandia multi-level polysilicon surface micromachining process [20]. An SEM cross-section of the friction pad is shown in Fig. 8. By comparing to Fig. $3 b$, the structure appears to have been successfully realized. In Fig. 8, note that the poly 3 is flat, in spite of the complicated topography beneath it. This can be achieved because our process includes chemical mechanical polishing (CMP) of the Sac Ox 3 layer. The width of the region where the slider pad makes contact with the poly 0 is $3 \mu \mathrm{m}$. This is dictated by the $2.0 \mu \mathrm{m}$ minimum width of the Sac Ox 3 cut, as well as alignment tolerances.

Devices were released in $1: 1 \mathrm{HCl}: \mathrm{HF}$, transferred to $\mathrm{H}_{2} \mathrm{O}_{2}$ and freed by supercritical $\mathrm{CO}_{2}$ drying [21]. After the $\mathrm{H}_{2} \mathrm{O}_{2}$ treatment, the surface is nominally hydrophilic, and a $1 \mathrm{~nm}$ oxide covers the surface. Electrical actuation performed under an interferometric microscope (monochromatic green light with $\lambda=547 \mathrm{~nm}$ ), such that deflections could be assessed. In Fig. 9, we show results of the effect of pad voltage on the deflections, with OV on the driver beam. With no voltage applied, we see that the structure is not flat - each fringe represents $\lambda / 2=274 \mathrm{~nm}$. By focusing up and down, we could determine that the structures are curved up

Fig. 9 Pulling down the friction pad with $V_{p}$. 
slightly. This is due to the stress gradient in the polysilicon. The driver beam shows small curvature from the stress gradient, while the curvature in the friction pad is substantially larger. In the friction pad area, a conformal poly 3 deposition fills in 4 of the $6 \mu \mathrm{m}$ height. (Poly 2 has negligible strain gradient, as could be determined by observing cantilever beams). Apparently due to the poly 3 being distributed over a $4 \mu \mathrm{m}$ thickness, the strain gradient in the friction pad is larger than in the driver beam.

By applying 3V, the friction pad is brought into contact with the substrate, Fig. 9b. At $10 \mathrm{~V}$, it is flat along most of its length, as seen in Fig. $9 \mathrm{c}$. Finally, at $25 \mathrm{~V}$, the beam is substantially flat. These results are in very good qualitative agreement with the spirit of the calculations presented in Fig. 5a. The main reason for the discrepancy in comparing the detailed deformations is due to the strain gradient of the poly 3.

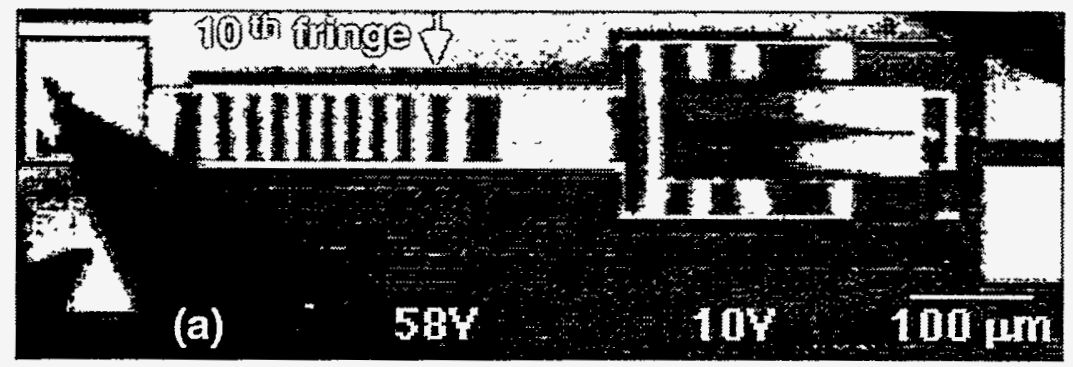

By now inducing driver beam deflections at different driver pad voltages, we can test whether the friction pad induces resistance to slip. For these tests, pad voltage was first applied. Then driver voltage was increased until the driver beam was near pull-in. After a given test, both voltages were

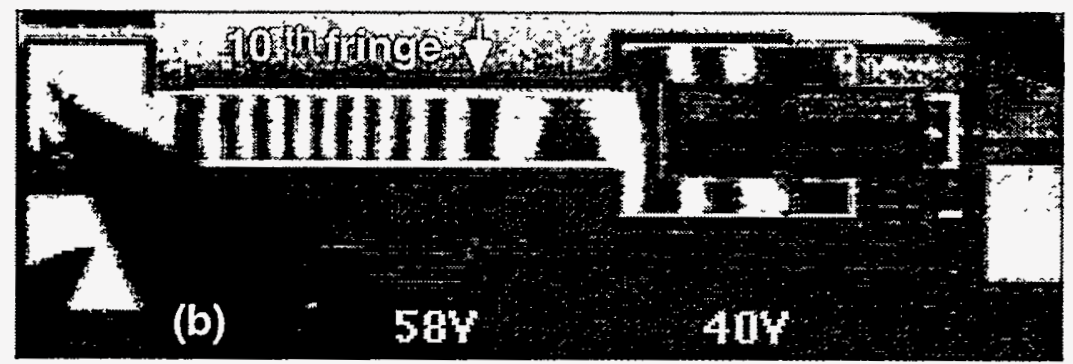
Fig. 10 Driver beam deflections for two different pad voltages relaxed. Usually, the friction pad freed itself from the substrate - adhesive forces are relatively low. In Fig. 10, beam deflections for $V_{d}=58$ and for $V_{p}=0 \mathrm{~V}$ and $40 \mathrm{~V}$ respectively are shown. Here, the length of the friction pad is $200 \mu \mathrm{m}$ rather than $600 \mu \mathrm{m}$ as in Fig. 9. Note that in Fig. 10a, there are approximately eleven fringes from the support post on the left hand side, while in Fig. 10b, there are only ten fringes. Therefore, comparison of the inteferograms in Figs. 10a and 10b suggests qualitatively that there is a difference in the slip for the two cases of $V_{p}=10 \mathrm{~V}$ and $40 \mathrm{~V}$, because the same driver voltage produces dissimilar deflection profiles.

To obtain a quantitative value of the slip, the deflections are first deduced from the fringe data. Linescans were taken along the driver beam from the pad to the slider, and also along one of the forked sections. Because the last segment of the driver beam near the slider, and the beginning segment of the fork overlap in $x$, these two sections were superposed to obtain the total deflection, as shown in Fig. 11a.

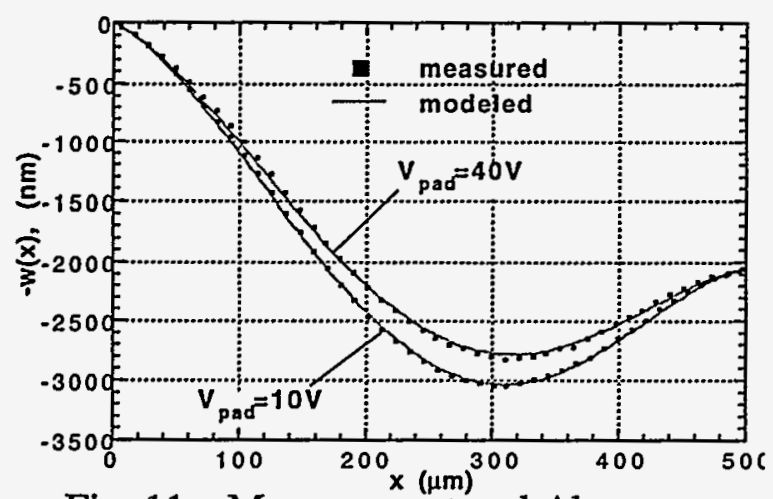

Fig. 11a Measurement and Abacus modeling for data in Fig. 10a
Numerical simulation is required to model the deflections because of charge redistribution along the length of the driver beam. The situation modeled is shown in Fig. 11b, where the axial load due to the friction is represented by $F_{\mathrm{p}}$.

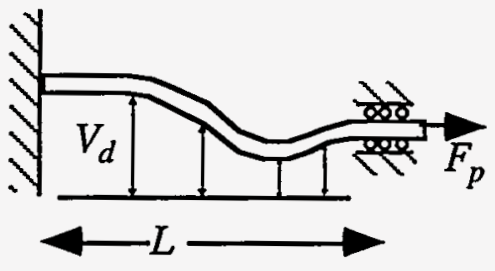

Fig. 11b Schematic of model to match measured deflections 
Paper to appear in SPIE v. 3512, Materials and Device Characterization in Micromachining, Santa Clara, CA

Table 1- Calculated parameters from the modeling

\begin{tabular}{ccccc}
\hline$V_{p}(\mathrm{~V})$ & Slip $(\mathrm{nm})$ & $F_{p}(\mu \mathrm{N})$ & $F_{n}(\mu \mathrm{N})$ & cof \\
\hline 10 & -4.56 & 350 & 45 & 7.8 \\
40 & 0.73 & 390 & 127 & $\geq 3.1$ \\
\hline
\end{tabular}

To infer slip distance, nonlinear finite element beam models were developed in Abaqus [22] to match the experimental data. The distributed electrostatic force was accurately modeled as a nonlinear deformation dependent capacitive loading, including a fringing field correction [23].

In order to obtain reasonable agreement with the data, the compliance of the support post and the hinge could not be ignored. Rather than estimating this compliance from the geometric structure, the slope near the extremes was measured and included in the modeling boundary conditions. Driver voltage $V_{d}$ was then applied, and force $F_{p}$ was increased until the deflections were matched. We see in Fig. 11a that excellent agreement between the simulation and the data is achieved.

As seen in Table 1, the modeling results indeed indicate there is a difference in slip of approximately $5 \mathrm{~nm}$ between the two cases. The values are relative to the slip after the pad has been brought into contact by pad voltage, and are negative for slip to the left. Slip to the right is not expected, therefore the value of $0.73 \mathrm{~nm}$ (which may be slightly off due to experimental error) for $V_{p}=40 \mathrm{~V}$ probably indicates that the pad has not initiated slip. The values for $F_{p}$ do not differ greatly. This apparently indicates that for $V_{p}=10 \mathrm{~V}, F_{p} \geq 350 \mu \mathrm{N}$ is required to initiate slip, while for $V_{p}=40 \mathrm{~V}$, a value of $F_{p}=390 \mu \mathrm{N}$ is insufficient.

Normal force $F_{n}$ in Table 1 is computed from sum of the point reaction force, $40 \mu \mathrm{N}$, and the distributed force. For $V_{p}=10 \mathrm{~V}$, most of the contribution is from the point loading, and the distribution of pressure is rather non-uniform. The pad is in contact only to the left of the hinge, therefore the approximate pressure is $\sim 150 \mathrm{KPa}$. However, over small variations in pressure, the cof is not generally expected to vary greatly. Keeping this in mind, the apparent cof $\sim$, is somewhat high compared to previous results. For $V_{p}=10 \mathrm{~V}, \operatorname{cof}=7.8$. This is a lower bound, because it is possible that $F_{p}$ must increase to move the pad further. The value compares to $\operatorname{cof}=2$ measured for a supercritically dried surface in ref. [13], and $c o f=5$ in ref. [14]. Further study is required to understand this high value. At $V_{p}=10 \mathrm{~V}, V_{d}=58 \mathrm{~V}$ is very near the pull-in voltage of the device.

For $V_{p}=40 \mathrm{~V}$ the pad is in contact along its entire length, and the value of $c o f=3.1$ is a lower bound because the slip apparently has not yet initiated. If the cof is truly 8, no slip is expected before pull-in at $V_{p}=40 \mathrm{~V}$. Such a high coefficient of friction limits the usage of this device as currently designed. Greater slip amplitude is possible by the principle of leveraged bending [24], and has been implemented in our next design. Calculations indicate the potential slip can be doubled at the expense of greater driver voltage. Also, we will apply molecular coatings [25] to these devices to lower the coefficient of friction in subsequent measurements.

A problem encountered in our current design is in the symmetry of the friction pad. As seen in Figs. $3 \mathrm{~b}$ and 8 , the pad is loaded symmetrically, which theoretically will give equal loading from each wing. However, a small difference due to geometry after etch or misalignment of poly 3 to poly 0 will cause the force to be unequal on the two sides, giving rise to positive feedback. This results in toppling of the device when the torsional resistance of the driver beam is overwhelmed. Depending on the device, the voltage on the friction pad has been limited to 30-50V maximum. Our follow-up design will employ a more stable friction pad configuration.

\section{Summary and Conclusions}

We have designed, modeled, fabricated and performed initial test measurements on a new structure to measure friction in micromachining. The device consists of a cantilevered forked beam and a friction pad attached via a hinge. The placement of the hinge is crucial to obtaining a well known and constant pressure distribution in the device. Compared to comb drive configurations, the current structure has a larger pressure range and occupies a much smaller area at the expense of range in slip. Furthermore, it has a very large velocity range [19]. Static deflections on the device 
were measured and modeled using Abaqus. With the oxide coating, slip of $5 \mathrm{~nm}$ was inferred shortly before pull-in. The observed cof $\sim 8$, limits the slip range due to stretching of the driver beam. The cof can be reduced by applying molecular coatings, enhancing the usefulness of the present device. To improve on the device, increased slip by leveraged bending and a more stable friction pad configuration will be implemented.

\section{Acknowledgements}

Sandia National Laboratories is a multiprogram laboratory operated by Sandia Corporation, a Lockheed-Martin Company, for the United States Department of Energy under Contract DEAC04-94AL85000. We thank the staff at the Microelectronics Development Laboratory at Sandia National Laboratories for fabricating and releasing the samples.

\section{Refeirences}

1. T. A. Roessig, R. T. Howe, A. P. Pisano and J. H. Smith, Transducers '97, Chicago, IL, USA, June 16-19, 1997, vol. 2, pp. 859-862.

2. T. Juneau, A. P. Pisano and J. H. Smith, Transducers '97, Chicago, IL, USA, June 16-19, 1997 , vol. 2, pp. 883-886.

3. A. Lawrence, Modern Inertial Technology, (Springer Verlag, New York, 1993).

4. L. J. Hornbeck, SPIE '95, Austin, TX, Austin, TX, Sept., 1995, vol. 2639, p. 2.

5. S. A. Henck, Tribology Letters 3, 239 (1997).

6. M. P. de Boer and T. A. Michalske, Mater. Res. Soc. Proc. 444, 87 (1997).

7. M. P. de Boer, P. J. Clews, B. K. Smith and T. A. Michalske, Mater. Res. Soc. Proc. 518 (in press), (1998).

8. M. P. de Boer et al., Mater. Res. Soc. Proc. (to be presented, Dec. 1998).

9. A. A. Yasseen, J. Mitchell, T. Streit, D. A. Smith and M. Mehregany, IEEE MEMS '98, Heidelberg, Germany, Jan. 25-29, 1998, pp. 116-120.

10. M. S. Rodgers and J. J. Sniegowski, Hilton Head '98, Hilton Head Island, SC, USA, June 8-11, 1998, pp. 144-149.

11. N. Tas, J. Wissink, L. Sander, T. Lammerink and M. Elwenspoek, Transducers '97, Chicago, IL, 1997, vol. 2, pp. 777-780.

12. T. Baumberger and C. Caroli, MRS Bull. 23 (6), 41 (1998).

13. U. Srinivasan et al., Hilton Head '98, Hilton Head Island, SC, USA, 1998, pp. 156-161.

14. M. G. Lim, J. C. Chang, D. P. Schultz, R. T. Howe and R. M. White, Proc. IEEE MEMS Workshop, Napa Valley, CA, USA, Feb. 11-14, 1990, pp. 82-88.

15. M. T. Dugger, personal communication (1997).

16. P. Osterberg, H. Yie, X. Cai, J. White and S. Senturia, IEEE '94, 1994, pp. 28-32.

17. M. P. de Boer, M. R. Tabbara, M. T. Dugger, P. J. Clews and T. A. Michalske, Transducers '97, Chicago, IL, USA, 1997, vol. 2, pp. 229-232.

18. X. Tian and B. Bhushan, J. Trib. 118, 33 (1996).

19. J. M. Redmond, M. P. de Boer and T. A. Michalske, ASME conference, Anaheim, CA, Nov. 1998, Anaheim, CA, to be presented, Nov., 1998,

20. E. Garcia and J. Sniegowski, Sensors and Actuators A 48, 203 (1995).

21. E. M. Russick, C. L. J. Adkins and C. W. Dyck, in Supercritical Fluids, Extraction and Pollution Prevention, M. A. Abraham and A. K. Sunol, ed. (American Chemical Society, Washington, DC, 1997), vol. 670, pp. 255-269.

22. Hibbit, Karlsson and Sorensen, . Inc., Providence, RI, USA,

23. R. M. Osterberg, R.K. Gupta, J.R. Gilbert and S.D. Senturia, Hilton Head '94, Hilton Head Island, SC, USA, June 8-11, 1994, pp. 184.

24. E. S. Hung and S. D. Senturia, Hilton Head '98, Hilton Head Island, SC, USA, June 8-11, 1998, pp. 83-86.

25. M. R. Houston, R. Maboudian and R. T. Howe, Hilton Head, Hilton Head Island, SC, USA, June 3-6, 1996, pp. 42-47. 